\title{
Study on influence of flow rates on voids in waxy crude oil subjected to dynamic and static cooling
}

\section{Girma T. Chala ${ }^{*}$, Shaharin A. Sulaiman ${ }^{1}$, Azuraien Japper-Jaafar ${ }^{1}$ and Wan Ahmad Kamil Wan Abdullah ${ }^{2}$}

${ }^{1}$ Department of Mechanical Engineering, Universiti Teknologi PETRONAS, Bandar Seri Iskandar, 31750 Tronoh, Perak, Malaysia

*Email: girma_tade@yahoo.com Phone: +60143956537; Fax: +6053656461

${ }^{2}$ Department of Radiology, Hospital Universiti Sains Malaysia, 16150 Kubang Kerian, Kelantan, Malaysia

\begin{abstract}
The assumption of constant yield stress in the conventional restart pressure equation neglects the effects of thermal shrinkage and gas voids formation, which in turn resulted in an over-designed production piping systems. This paper presents a study on the effects of flow rates on the formation of voids in gelled waxy crude oil. A flow loop rig simulating offshore waxy crude oil transportation was used to produce a gel. A Magnetic Resonance Imaging (MRI) was used to scan the gelled crude oil over the three planes. Waxy crude oil underwent both dynamic and static cooling to observe the effects of volume flow rates on the voids formed in wax-oil gel. Volume flow rate was found to have different influences on the intra-gel voids in the pipeline. A volume flow rate of $5 \mathrm{~L} / \mathrm{min}$ resulted in a maximum total voids volume of $6.98 \%$ while $20 \mathrm{~L} / \mathrm{min}$ produced a minimum total voids volume of $5.67 \%$ in the entire pipe. Slow flow rates resulted in a larger voids volume near the pipe wall. In contrast, faster flow rates produced insignificantly higher voids volume around pipe core. Generally, slower flow rates favoured the formation of higher total voids volume following sufficient steady time of wax crystal formation, producing larger voids areas in gelled waxy crude oil.
\end{abstract}

Keywords: Waxy crude oil; Volume flow rate; Gas voids; dynamic cooling; static cooling.

\section{INTRODUCTION}

When a waxy crude oil flows through a sub-sea pipeline resting on the cold ocean floor, the temperature of the waxy crude oil drops below the wax appearance temperature (WAT) due to cold surrounding temperature [1-3]. Waxy crude oil behaves as a Newtonian fluid above the wax appearance temperature, over which a viscosity is not a function of temperature [4-6]. As the temperature further drops, the wax within the waxy crude oil starts precipitating, forming gelled crude oil below the pour point temperature. Lionetto et al. [7] reported that small wax contents would lead to the gelation of waxy crude oil, which results in phase transition and gel formation in pipelines. Waxy crude oil was reported to undergo thermal shrinkage, in which gas voids appeared and the fluid became multiphase and unusually compressible $[8,9]$. A reduced volume of waxy-oil gel during cooling was also recently observed to result in local voids in the gel. As a result, the non-uniform gel formation in pipelines could significantly reduce the pressure required to break the gel [7]. Cazaux et al. [10] investigated a gel structure using an X- 
ray diffraction (XRD) technique. They reported that crystal shape and the number density of wax crystal were found to define the structure of wax-oil gel, where both would depend on different cooling parameters. The size and shape of wax crystals in waxy crude oil also depend on the shear rate [11].

Henault et al. [12] studied the thermal shrinkage of waxy crude oil using X-ray scanning on different cross sections of a pipe. They stated that thermal shrinkage would greatly impact the mechanical properties of gelled crude oil. A reduced volume of waxyoil gel while cooling was also observed, which resulted in the formation of voids within the gel. Numerous researches highlighted that experimental investigation on the effects of flow properties of waxy crude oil on the formation of gas voids is required to understand the nature of gel strength. However, there have been no results reported showing the effects of volume flow rate on the formation of intra-gel voids during dynamic and static cooling. The objective of this work was, therefore, to observe the effects of volume flow rate on the formation of voids in waxy crude oil subjected to both dynamic and static cooling. It also aimed to determine the preferred optimum flow rate when normal shutdown is to take place.

\section{EXPERIMENTAL SETUP AND TECHNIQUES}

Figure 1 shows the schematic of a flow loop rig simulating offshore waxy crude oil transportation. A crude oil tank was equipped with a $12 \mathrm{~kW}$ capacity heater and a stirrer motor. The heater used had a capacity of heating the waxy crude oil up to $100^{\circ} \mathrm{C}$, which was well above the wax appearance temperature (WAT) of the sample used. The heating process, besides changing the phase and properties of the fluid, standardizes the flow by removing all the shear and thermal histories encountered during cooling. A gear pump (MAA 90L6-B3) with a maximum discharge pressure of 2.0 bar was mounted in the system to initiate the flow of waxy crude oil inside the rig. A pressure transmitter (WIKA A-10) that reads pressure ranges between $0-2.5$ bar was also installed at the inlet of the test section pipe to address the pressure developed in the gear pump. A Coriolis flow meter was used to measure the volume flow rate of waxy crude oil including its corresponding density in a test section pipe. The test section pipe was a detachable circular acrylic pipe of $30 \mathrm{~mm}$ in diameter and $1200 \mathrm{~mm}$ in length. Figure 2 shows the MRI used to scan gelled waxy crude oil in the detachable test section pipe. The MRI mainly generates images of the gelled crude oil in three views: axial, sagittal and coronal.

Table 1. Details of experiments conducted.

\begin{tabular}{ccccc}
\hline $\begin{array}{c}\text { Volume flow } \\
\text { rates }(\mathrm{L} / \mathrm{min})\end{array}$ & $\begin{array}{c}\text { Initial } \\
\text { Temperature } \\
\left({ }^{\circ} \mathrm{C}\right)\end{array}$ & $\begin{array}{c}\text { End } \\
\text { Temperature } \\
\left({ }^{\circ} \mathrm{C}\right)\end{array}$ & $\begin{array}{c}\text { End Temp for } \\
\text { dynamic cooling } \\
\left({ }^{\circ} \mathrm{C}\right)\end{array}$ & $\begin{array}{c}\text { Cooling } \\
\text { Time }(\mathrm{min})\end{array}$ \\
\hline 5 & 80 & 15 & WAT & 190 \\
7.5 & 80 & 15 & WAT & 195 \\
10 & 80 & 15 & WAT & 200 \\
15 & 80 & 15 & WAT & 203 \\
20 & 80 & 15 & WAT & 210 \\
\hline
\end{tabular}

A liquid waxy crude oil was made to flow at different volume flow rates into the test section pipe under cooling mode. The temperature of the waxy crude oil then dropped to wax appearance temperature under dynamic cooling, after which static cooling took 
place until its end temperature. Waxy crude oil gel at the same end temperatures were then scanned in the MRI. The initial and end temperatures of the waxy crude oil were kept constant to observe the effects of volume flow rates. The volume flow rates were 5 , $7.5,10,15$ and $20 \mathrm{~L} / \mathrm{min}$. Volume flow rates lower than $10 \mathrm{~L} / \mathrm{min}$ were considered as slower flow rates while faster flow rates represented the volume flow rates above 10 $\mathrm{L} / \mathrm{min}$. The voids formed as a result of these volume flow rates were compared. Table 1 shows the details of the experiments conducted. Figure 3 shows profiles of volume flow rates of waxy crude oil while cooling.

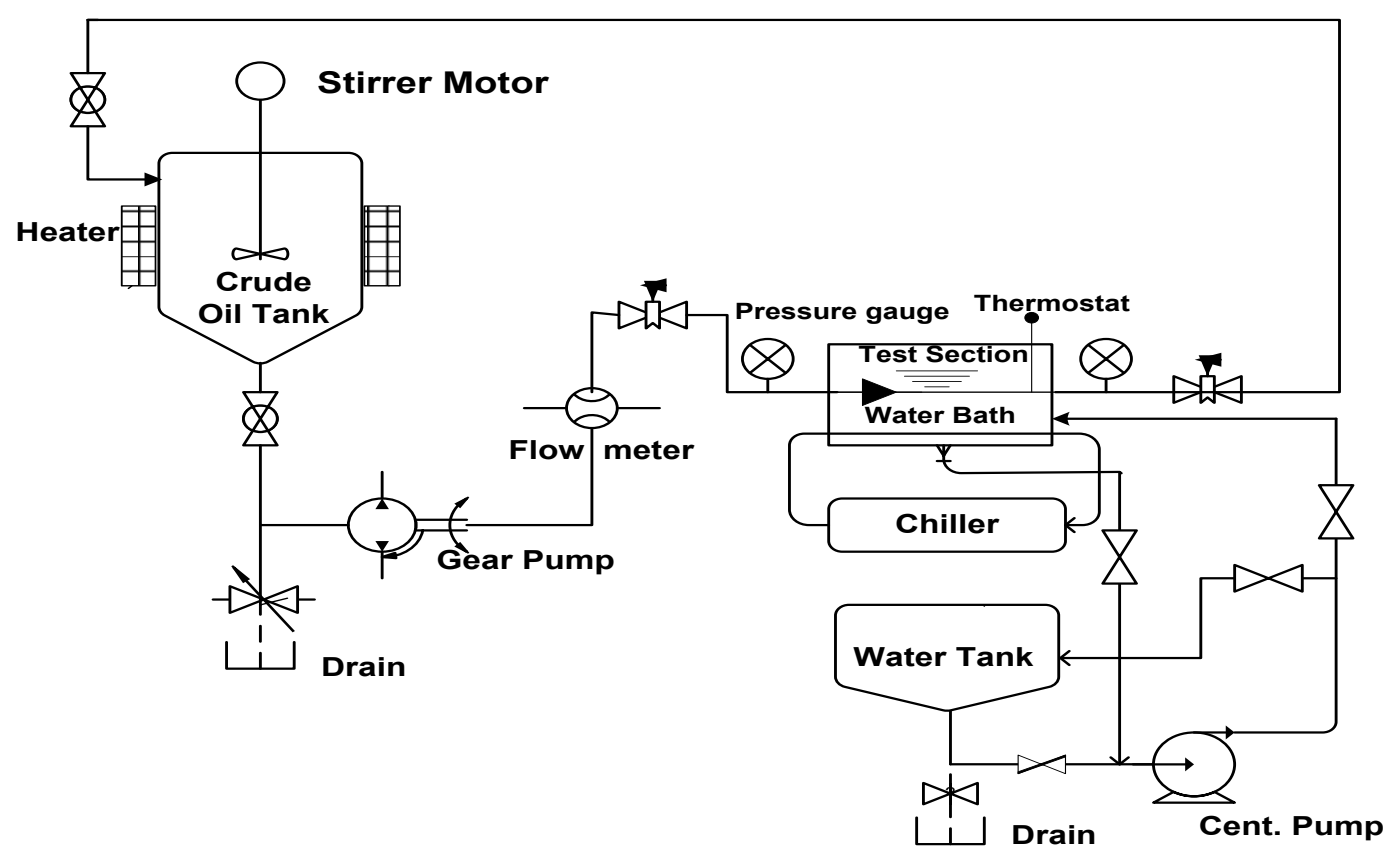

Figure 1. Schematic of the experimental set-up.

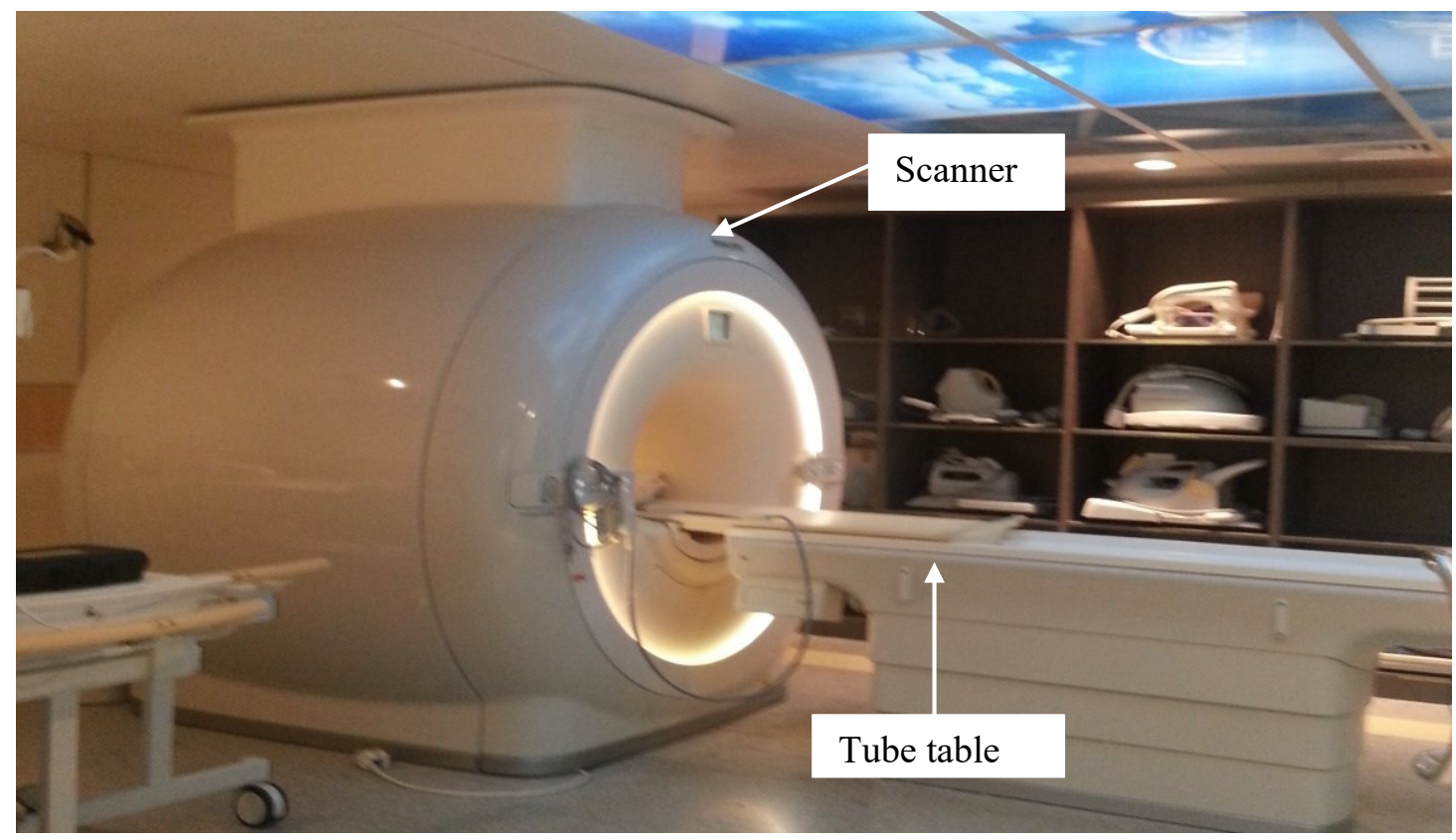

Figure 2. MRI used to scan gelled crude oil. 


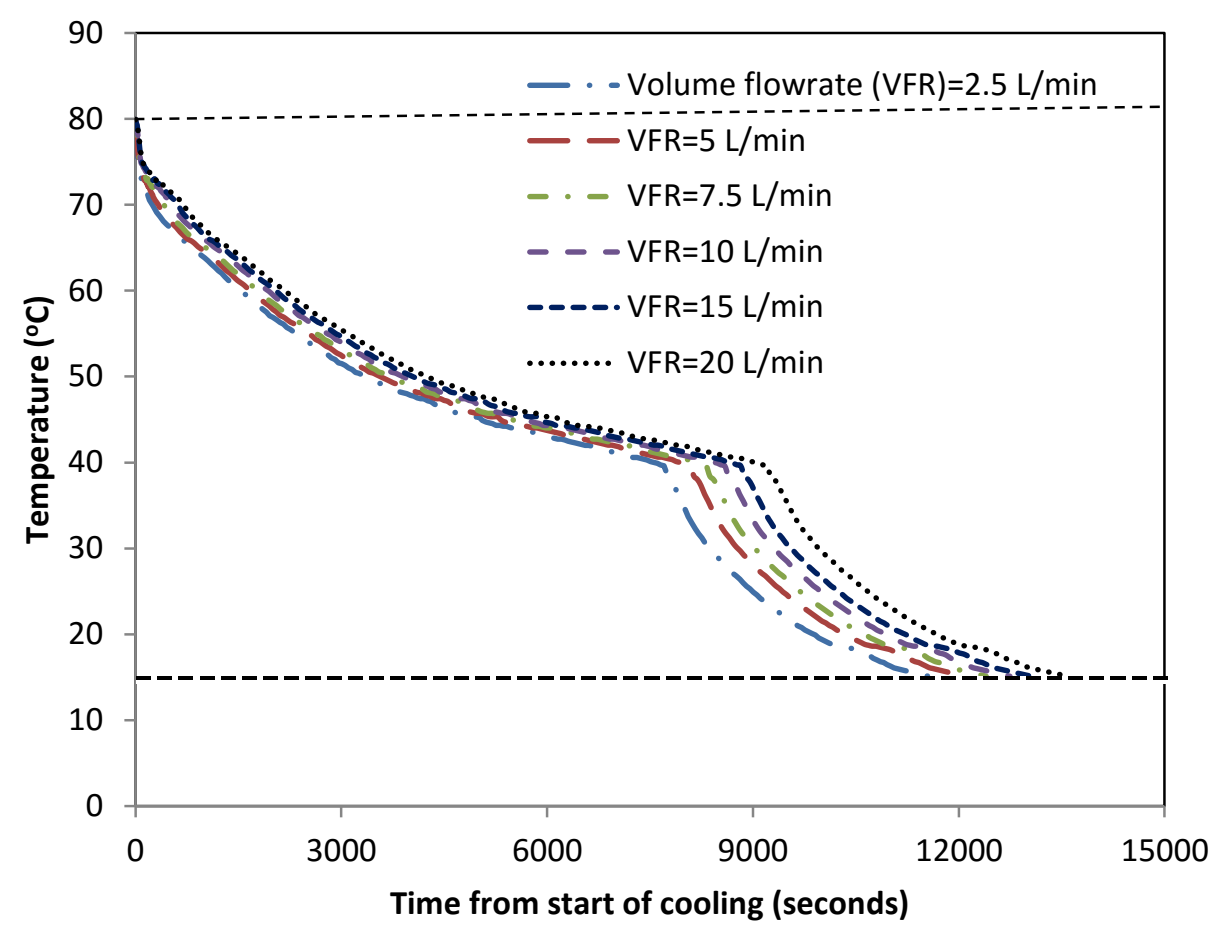

Figure 3. Profiles of temperature and volume flow rates of waxy crude oil.

\section{RESULTS AND DISCUSSION}

\section{Effects of Volume Flow Rate on Voids near Pipe Wall and Core}

The effects of volume flow rate on voids near the pipe wall were investigated. Figure 4(a) shows the resulting gas voids areas distribution near the pipe wall. Volume flow rates were observed to have different effects on the voids formed in the gelled crude oil. Faster flow rates generally produced lower void areas near the pipe wall, which was apparently evidenced at the region around the inlet of the pipe. A volume flow rate of $15 \mathrm{~L} / \mathrm{min}$ resulted in minimum voids cross sectional areas compared to other flow rates. In another view, a volume flow rate of $5 \mathrm{~L} / \mathrm{min}$ produced higher voids cross sectional areas over the region from the middle to the outlet of the scanned pipe, followed by $7.5 \mathrm{~L} / \mathrm{min}$ and 10 $\mathrm{L} / \mathrm{min}$. A minimum voids volume of $4.88 \%$ was estimated at $15 \mathrm{~L} / \mathrm{min}$ while a maximum voids volume of $6.43 \%$ was formed at $5 \mathrm{~L} / \mathrm{min}$ volume flow rate, inversely relating voids volume with volume flow rate at this region. Moreover, it was generally observed that the slower flow rates that flow slowly and steadily allow for the higher wax crystal formation and hence resulted in larger voids areas distribution along and across the pipeline. The variation between voids areas was also found insignificant at the outlet section while it was apparent at the inlet side of the scanned pipe. Effects of flow rates on the formation of voids around the pipe core were also investigated. Figure 4(b) shows the distribution of voids areas around the pipe core. A volume flow rate of $15 \mathrm{~L} / \mathrm{min}$ produced the largest voids areas over the pipe region ranging from the inlet to the middle of the pipe, with a maximum voids area of $10 \mathrm{~mm}^{2}$ observed at $-45.4 \mathrm{~mm}$ of the pipe. Contrary to the voids formed near the pipe wall, lower volume flow rates were also observed forming higher voids areas around the pipe core. However, volume flow rate of $5 \mathrm{~L} / \mathrm{min}$ resulted in the smallest total voids areas around the midpoint of the pipe, with nil voids size at $0 \mathrm{~mm}$ of the pipe. In addition, the boundary volume flow rate of $10 \mathrm{~L} / \mathrm{min}$ also resulted in a 
minimum voids areas around the outlet region of the pipe, which makes the trends of voids formation around core indefinite and further insignificant as compared to that near the pipe wall. Moreover, the voids size difference between faster and slower flow rates could also be influenced by the nature of voids as the voids mainly started forming in the non-Newtonian region as reported in [13].

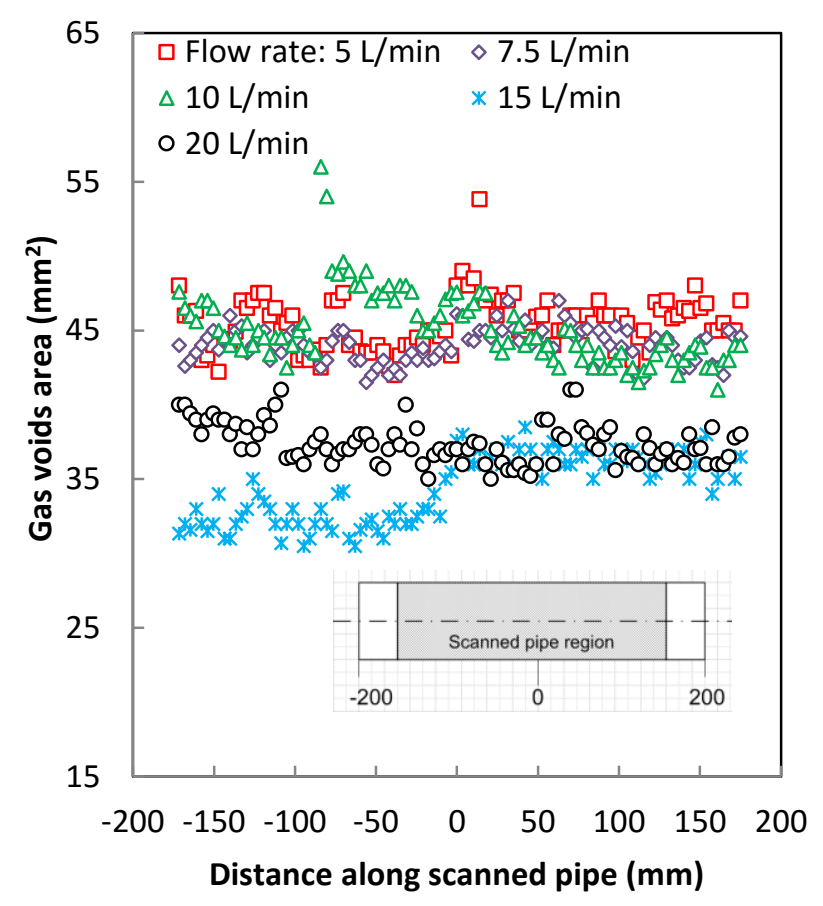

(a)

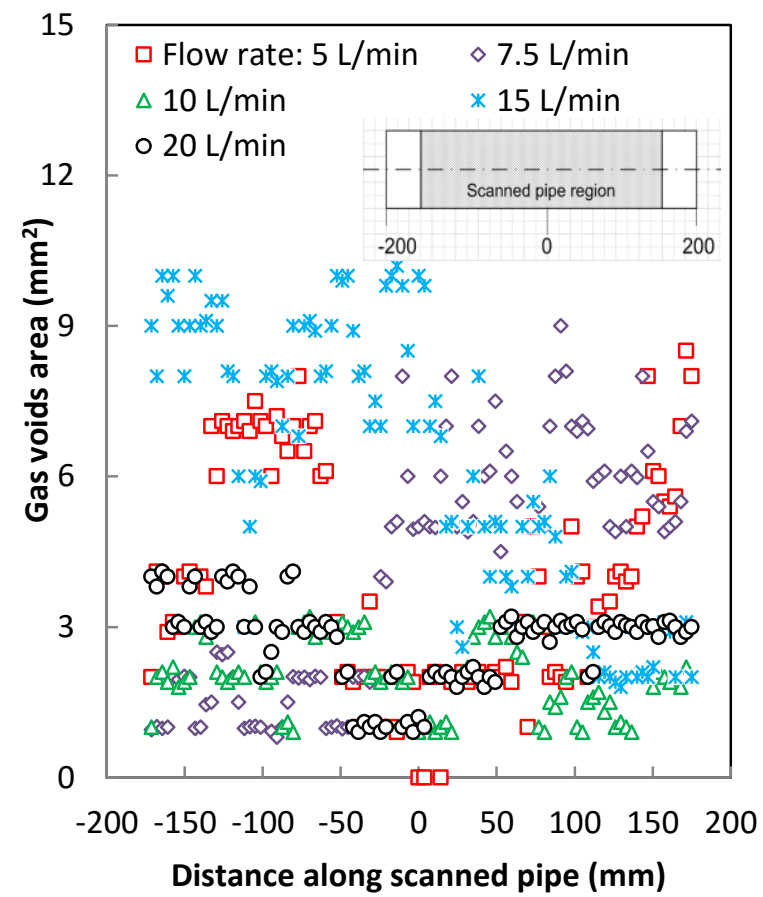

(b)

Figure 4. Gas voids area (a) near pipe wall and (b) pipe core.

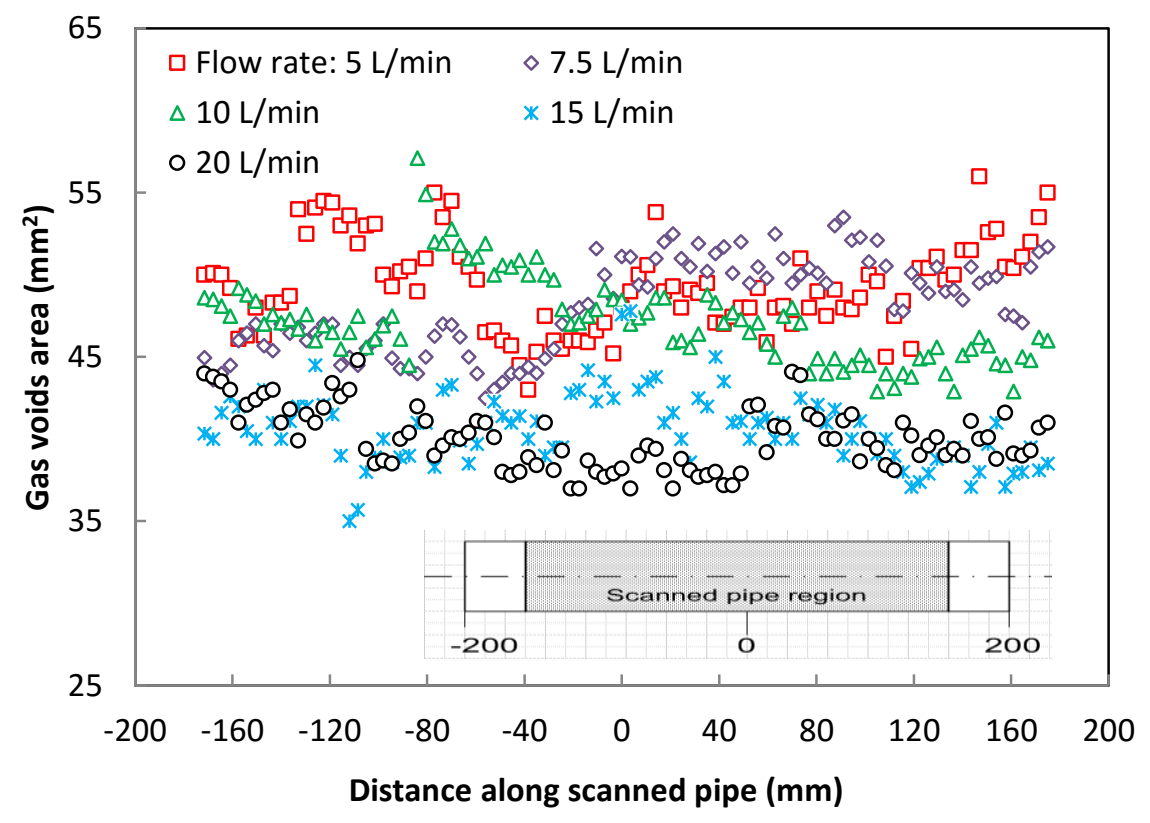

Figure 5. Voids areas in entire pipe. 


\section{Volume Flow Rates and Total Voids in the Pipe}

The effects of volume flow rate on total voids in the entire pipe were analysed by calculating total voids areas at different cross sections of the scanned pipe. Figure 5 shows total voids area for the different volume flow rates. Faster volume flow rates resulted in lower voids cross sectional areas. The voids areas distribution was not uniform that a volume flow rate of $20 \mathrm{~L} / \mathrm{min}$ produced the minimum voids areas in the scanned pipe region from $-45.5 \mathrm{~mm}$ to $49 \mathrm{~mm}$. The minimum volume flow rate of $5 \mathrm{~L} / \mathrm{min}$ was observed forming the largest voids areas throughout the scanned pipe, mainly at the two ends of the pipe. Volume flow rate of less than $10 \mathrm{~L} / \mathrm{min}$ produced higher voids areas over many cross sections than that for faster flow rates, indicating that the steady flow helped form a higher wax crystal formation and hence larger voids areas along and across the pipeline. In addition, the higher voids volume resulted during slow rates would reduce the pressure required to restart the clogged gel in pipelines.

\section{Comparisons of Voids Volume between Wall and Core}

Percentages of voids volume near the pipe wall, around pipe core, and in the entire pipe following dynamic and static cooling are compared. Figure 6 shows volume flow rates versus voids volume in percent at different regions in the pipe. Slower flow rates produced higher voids volume near the pipe wall. A similar result was also observed for the total voids volume that was found significant at slower flow rates. A maximum voids volume of $6.98 \%$ and $6.43 \%$ were measured in the entire pipe and near the pipe wall, respectively, at the minimum volume flow rate of $5 \mathrm{~L} / \mathrm{min}$. Faster flow rates generally formed smaller voids volume, which in another way predicts a higher voids volume when the waxy crude oil flows at slower volume flow rates. The slower flow rates would give enough steady time that would in turn give sufficient time for the voids formation, resulting in larger voids in the gel. For the voids around the pipe core, no definite trend was observed with a minimum amount of voids volume measured at $10 \mathrm{~L} / \mathrm{min}$ and a maximum of $0.87 \%$ void volume produced at $15 \mathrm{~L} / \mathrm{min}$, which is in contrast to the trend of voids formation near the pipe wall.

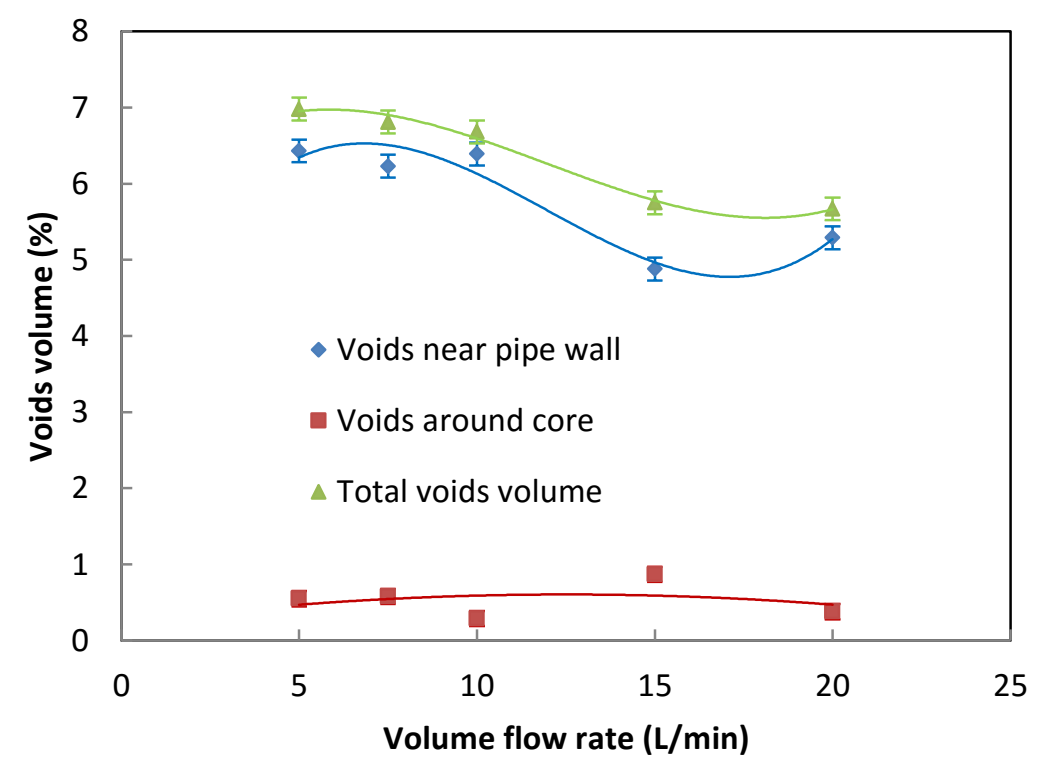

Figure 6. Percentage of voids volume at different volume flow rates. 


\section{CONCLUSIONS}

Waxy crude oil flowing at different flow rates had undergone dynamic cooling to its wax appearance temperature and further to its end temperature under static cooling. The effects of volume flow rate of waxy crude oil on the formation of intra-gel voids were studied using the MRI system and the flow loop rig developed. The gelled crude oil at the same end temperature was scanned to investigate the flow rates effects on the voids formed. The results from the quantitative study showed that volume flow rate had different effects on the formation of intra-gel voids along and across the pipeline. Volume flow rate of $5 \mathrm{~L} / \mathrm{min}$ produced a maximum total voids volume of $6.98 \%$ while $20 \mathrm{~L} / \mathrm{min}$, which was the maximum volume flow rate tested, resulted in a minimum total voids volume of $5.67 \%$ in the entire pipe, inversely correlating voids volume with the volume flow rate. Slower flow rates were generally found producing higher voids volume near the pipe wall and in the entire pipe, which would make the restart pressure to be lower than those of faster rates.

\section{ACKNOWLEDGEMENTS}

The authors would like to thank Universiti Teknologi PETRONAS and YUTP grant with Project Cost Centre No. 0153AA-A22/23 for sponsoring the research work and Hospital Universiti Sains Malaysia (HUSM) for providing access and assistance in the use of the 3T-MRI.

\section{REFERENCES}

[1] Zhao Y, Kumar L, Paso K, Safieva J, Sariman MZB, Sjöblom J. Gelation behavior of model wax-oil and crude oil systems and yield stress model development. Energy and Fuels. 2012;26:6323-31.

[2] Aiyejina A, Chakrabarti DP, Pilgrim A, Sastry MKS. Wax formation in oil pipelines: A critical review. International Journal of Multiphase Flow. 2011;37:671-94.

[3] Chala GT, Sulaiman SA, Japper-Jaafar A, Kamil Wan Abdullah WA, Mior Mokhtar MM. Gas void formation in statically cooled waxy crude oil. International Journal of Thermal Sciences. 2014;86:41-7.

[4] Margarone M, Bennardo A, Busto C, Correra S. Waxy oil pipeline transportation through cold flow technology: Rheological and pressure drop analyses. Energy and Fuels. 2012;27:1809-16.

[5] Mortazavi-Manesh S, Shaw JM. Thixotropic rheological behavior of maya crude oil. Energy and Fuels. 2014;28:972-9.

[6] Chala GT, Sulaiman SA, Japper-Jaafar A, Abdullah WAKW. Impacts of cooling rates on voids in waxy crude oil under quiescent cooling mode. Applied Mechanics and Materials. 2015;799-800:62-6.

[7] Lionetto F, Coluccia G, D'Antona P, Maffezzoli A. Gelation of waxy crude oils by ultrasonic and dynamic mechanical analysis. Rheologica Acta. 2007;46:601-9.

[8] Lee HS, Singh P, Thomason WH, Fogler HS. Waxy oil gel breaking mechanisms: adhesive versus cohesive failure. Energy and Fuels. 2007;22:480-7.

[9] Chala GT, Sulaiman SA, Japper-Jaafar A, Abdullah WAKW. Effects of cooling regime on the formation of voids in statically cooled waxy crude oil. International Journal of Multiphase Flow. 2015;77:187-95. 
[10] Cazaux G, Barre L, Brucy F. Waxy crude cold start: Assessment through gel structural properties. SPE Annual Technical Conference and Exhibition, 27-30 September, New Orleans, Louisiana, USA: Society of Petroleum Engineers; 1998.

[11] Bordalo SN, Oliveira RD. Experimental study of oil/water flow with paraffin precipitation in submarine pipelines. Society of Petroleum Engineers.

[12] Hénaut I, Vincké O, Brucy F. Waxy Crude oil restart: Mechanical properties of gelled oils. SPE Annual Technical Conference and Exhibition, Houston, Texas, USA: Society of Petroleum Engineers; 1999.

[13] Ahmadpour A, Sadeghy K, Maddah-Sadatieh S-R. The effect of a variable plastic viscosity on the restart problem of pipelines filled with gelled waxy crude oils. Journal of Non-Newtonian Fluid Mechanics. 2014;205:16-27. 